\title{
Association of gene polymorphisms with chronic kidney disease in high- or low-risk subjects defined by conventional risk factors
}

\author{
TETSURO YOSHIDA ${ }^{1}$, KIMIHIKO KATO $^{2}$, KIYOSHI YOKOI $^{2}$, MITSUTOSHI OGURI $^{3}$, SACHIRO WATANABE $^{4}$, \\ NORIFUMI METOKI ${ }^{5}$, HIDEMI YOSHIDA ${ }^{6}$, KEI SATOH $^{6}$, YUKITOSHI AOYAGI $^{7}$, \\ YUTAKA NISHIGAKI $^{7}$, YOSHINORI NOZAWA ${ }^{8}$ and YOSHIJI YAMADA ${ }^{9}$ \\ ${ }^{1}$ Department of Cardiovascular Medicine, Inabe General Hospital, Inabe; ${ }^{2}$ Department of Cardiovascular Medicine, \\ Gifu Prefectural Tajimi Hospital, Tajimi; ${ }^{3}$ Department of Cardiology, Japanese Red Cross Nagoya First Hospital, \\ Nagoya; ${ }^{4}$ Department of Cardiology, Gifu Prefectural General Medical Center, Gifu; ${ }^{5}$ Department of Internal Medicine, \\ Hirosaki Stroke Center, Hirosaki; ${ }^{6}$ Department of Vascular Biology, Institute of Brain Science, Hirosaki University \\ Graduate School of Medicine, Hirosaki; ${ }^{7}$ Department of Genomics for Longevity and Health, Tokyo Metropolitan \\ Institute of Gerontology, Tokyo; ${ }^{8}$ Gifu International Institute of Biotechnology, Kakamigahara; ${ }^{9}$ Department of \\ Human Functional Genomics, Life Science Research Center, Mie University, Tsu, Japan
}

Received December 17, 2008; Accepted February 19, 2009

DOI: 10.3892/ijmm_00000193

\begin{abstract}
The purpose of the present study was to identify genetic variants which confer susceptibility to chronic kidney disease (CKD) in high- or low-risk subjects defined by conventional risk factors separately. The study population comprised 2828 Japanese individuals, including 434 subjects with CKD [estimated glomerular filtration rate (eGFR) $<60 \mathrm{ml} / \mathrm{min} / 1.73 \mathrm{~m}^{2}$ ] and 2394 controls $(\mathrm{eGFR} \geq 60 \mathrm{ml} / \mathrm{min} /$ $1.73 \mathrm{~m}^{2}$ ). The 1012 high-risk subjects had both hypertension and diabetes mellitus, and the 1816 low-risk subjects had none of these conditions. The genotypes for 296 polymorphisms of 202 candidate genes were determined. The Chi-square test, multivariable logistic regression analysis with adjustment for covariates, as well as a stepwise forward selection procedure revealed that ten different polymorphisms were associated $(\mathrm{P}<0.05)$ with the prevalence of CKD in high- or low-risk subjects: the $-519 \mathrm{~A} \rightarrow \mathrm{G}$ polymorphism of $M M P 1$, the $1061 \mathrm{~A} \rightarrow \mathrm{G}$ (Ile405Val) polymorphism of CETP, the $\mathrm{A} \rightarrow \mathrm{G}$ (Lys45Glu) polymorphism of $M M P 3$, the $-219 \mathrm{G} \rightarrow \mathrm{T}$ polymorphism of $A P O E$, the $\mathrm{A} \rightarrow \mathrm{G}$ (Ile1205Val) polymorphism of COL3A1, the $-863 \mathrm{C} \rightarrow \mathrm{A}$ polymorphism of $T N F$, and the $1454 \mathrm{C} \rightarrow \mathrm{G}$ (Leu $125 \mathrm{Val}$ ) polymorphism of PECAM1 in high-risk subjects; and the $1167 \mathrm{C} \rightarrow \mathrm{T}$ (Asn389Asn) polymorphism of $T G F B R 2$, the $2386 \mathrm{~A} \rightarrow \mathrm{G}$ (Ile796Val) polymorphism of $S C A P$, and the TAAA $\rightarrow$ del polymorphism of $P D E 4 D$ in low-risk
\end{abstract}

Correspondence to: Dr Yoshiji Yamada, Department of Human Functional Genomics, Life Science Research Center, Mie University, 1577 Kurima-machiya, Tsu, Mie 514-8507, Japan

E-mail: yamada@gene.mie-u.ac.jp

Key words: genetics, polymorphism, chronic kidney disease, endstage renal disease subjects. Among these polymorphisms, the $-519 \mathrm{~A} \rightarrow \mathrm{G}$ polymorphism of $M M P 1$ and the $1167 \mathrm{C} \rightarrow \mathrm{T}$ (Asn389Asn) polymorphism of TGFBR2 were most significantly associated with CKD in high- or low-risk individuals, respectively. These results suggest that polymorphisms associated with CKD may differ among high- or low-risk subjects. Stratification of subjects according to conventional risk factors may thus be important for personalized prevention of CKD based on genetic information.

\section{Introduction}

Chronic kidney disease (CKD) has been recognized as a global public health problem; individuals with CKD are at increased risk not only for end-stage renal disease (ESRD) but also for a poor cardiovascular outcome and premature death $(1,2)$. It is usually associated with conventional risk factors, including hypertension and diabetes mellitus (3-6). In the large percentage of CKD cases, which occur in the setting of hypertension or diabetes mellitus, arteriosclerosis seems to be a major pathogenic mechanism (7). However, susceptibility to CKD varies considerably among individuals with known risk factors, suggesting a role for genetic factors other than those that influence high blood pressure, hyperglycemia, or other conventional risk factors for arteriosclerosis. This has been demonstrated in animal models (8) and suggested in humans by the disproportionate burden of ESRD among black individuals which may not be explained by greater prevalence or severity of hypertension or diabetes mellitus (9). In general, individuals with hypertension and diabetes mellitus and those with none of these factors are considered at high- or low-risk, respectively, for development of CKD. It is thus important to identify genes that confer susceptibility to CKD in high- or low-risk individuals independently. Disease prevention is an important strategy for reducing the overall burden of CKD and ESRD, and the identification of markers for disease risk 
is key both for risk prediction and for potential intervention to reduce the chance of future cardiovascular events (10).

Although genetic linkage analyses (11) and association studies (12-14) have implicated several loci and candidate genes in predisposition to $\mathrm{CKD}$, the genes that contribute to genetic susceptibility to CKD in high- or low-risk subjects remain largely unknown. In addition, given the ethnic differences in lifestyle and environmental factors as well as in genetic background, it is important to examine genetic variants related to $\mathrm{CKD}$ in high- or low-risk individuals of each ethnic group. We now performed an association study for 296 polymorphisms of 202 candidate genes and CKD in 2828 Japanese individuals in the absence or presence of hypertension and diabetes mellitus. The purpose of the present study was to identify genetic variants that confer susceptibility to CKD in high- or low-risk subjects independently and thereby to assess the genetic risk of CKD in such individuals separately.

\section{Materials and methods}

Study population. The study population comprised 2828 unrelated Japanese individuals (1535 men, 1293 women) who either visited outpatient clinics of or were admitted to one of the participating hospitals (Gifu Prefectural General Medical Center and Gifu Prefectural Tajimi Hospital in Gifu Prefecture, Japan; and Hirosaki University Hospital, Reimeikyo Rehabilitation Hospital, and Hirosaki Stroke Center in Aomori Prefecture, Japan) between October 2002 and March 2008 because of various symptoms or for an annual health checkup, or who were recruited to a population-based prospective cohort study of aging and age-related diseases in Gunma Prefecture and Tokyo, Japan.

Glomerular filtration rate was estimated with the use of the simplified prediction equation derived from the modified version of that described in the Modification of Diet in Renal Disease (MDRD) Study as proposed by the Japanese Society of Nephrology (15): eGFR ( $\left.\mathrm{ml} \mathrm{min} \mathrm{m}^{-1} 1.73 \mathrm{~m}^{-2}\right)=194 \mathrm{x}$ [age

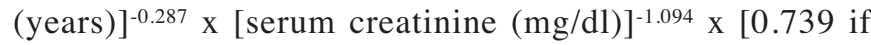
female]. The National Kidney Foundation-Kidney Disease Outcomes Quality Initiative guidelines recommend a diagnosis of CKD if eGFR is $<60 \mathrm{ml} \mathrm{min}{ }^{-1} 1.73 \mathrm{~m}^{-2}(10)$. Nonlinear relations between GFR and the risk of adverse events, such as death, cardiovascular events, and hospitalization, have been demonstrated, with an increased risk being associated with an eGFR of $<60 \mathrm{ml} \mathrm{m^{-1 }} 1.73 \mathrm{~m}^{-2}$ (16). We thus adopted the criterion of an eGFR of $<60 \mathrm{ml} \mathrm{min}^{-1} 1.73 \mathrm{~m}^{-2}$ for diagnosis of CKD in the present study. On the basis of this criterion, 434 subjects (263 men, 171 women) were diagnosed with CKD. The control subjects comprised 2394 individuals (1272 men, 1122 women) whose eGFR was $\geq 60 \mathrm{ml} \mathrm{min}^{-1} 1.73 \mathrm{~m}^{-2}$. The control subjects were recruited from community-dwelling healthy individuals or the patients who visited outpatient clinics regularly for treatment of various common diseases. Subjects with CKD and controls thus either had or did not have conventional risk factors for CKD, including hypertension (systolic blood pressure of $\geq 140 \mathrm{mmHg}$ or diastolic blood pressure of $\geq 90 \mathrm{mmHg}$, or both, or taking antihypertensive medication), diabetes mellitus (fasting blood glucose of $\geq 6.93 \mathrm{mmol} / 1$ or hemoglobin $\mathrm{A} 1 \mathrm{c}$ of $\geq 6.5 \%$, or both, or taking antidiabetes medication), or hypercholesterolemia (serum total cholesterol of $\geq 5.72 \mathrm{mmol} / 1$ or taking lipidlowering medication). Among all 2828 study subjects, the 1012 individuals (668 men, 344 women) with both hypertension and diabetes mellitus were classified as high-risk subjects, and the 1816 individuals (867 men, 949 women) with none of these conditions were classified as low-risk subjects.

The study protocol complied with the Declaration of Helsinki and was approved by the Committees on the Ethics of Human Research of Mie University Graduate School of Medicine, Hirosaki University Graduate School of Medicine, Gifu International Institute of Biotechnology, Tokyo Metropolitan Institute of Gerontology, and participating hospitals. Written informed consent was obtained from each participant.

Selection of polymorphisms. Our aim was to identify genes associated with CKD in the Japanese population in a casecontrol association study by examining the relations of one to five polymorphisms of each candidate gene to this condition. With the use of public databases, including PubMed (NCBI) and Online Mendelian Inheritance in Man (OMIM), we selected 202 candidate genes which have been characterized and suggested to be associated with CKD. On the basis of published studies or by searching PubMed and single nucleotide polymorphism (SNP) databases [dbSNP (NCBI) and Japanese SNP database (JSNP)], we further selected 296 polymorphisms of these genes, most located in the promoter region or exons, that might be expected to result in changes in the function or expression of the encoded protein (data not shown).

Genotyping of polymorphisms. Venous blood $(7 \mathrm{ml})$ was collected in tubes containing $50 \mathrm{mmol} / 1$ ethylenediaminetetraacetic acid (disodium salt), and genomic DNA was isolated with a kit (Genomix; Talent, Trieste, Italy). Genotypes of the 296 polymorphisms were determined at G\&G Science (Fukushima, Japan) by a method that combines the polymerase chain reaction (PCR) and sequence-specific oligonucleotide probes with suspension array technology (Luminex, Austin, TX). Detailed genotyping methodology was described previously (17).

Statistical analysis. Quantitative data were compared between subjects with CKD and controls in high- or low-risk subjects by the unpaired Student's t-test. Categorical data were compared by the Chi-square test. Allele frequencies were estimated by the gene counting method. In the initial screen, the genotype distributions $(3 \times 2)$ or allele frequencies $(2 \times 2)$ of each polymorphism were compared between subjects with CKD and controls in high- or low-risk subjects by the Chisquare test. Multivariable logistic regression analysis was then performed with CKD as a dependent variable and independent variables including age, gender (0, woman; 1 , man), body mass index (BMI), smoking status ( 0 , nonsmoker; 1 , smoker), history of hypercholesterolemia ( 0 , no history; 1 , positive history), and genotype of each polymorphism; the P-value, odds ratio, and $95 \%$ confidence interval were calculated. Each genotype was assessed according to dominant, recessive, 
Table I. Characteristics of subjects with chronic kidney disease (CKD) and controls in the present study.

\begin{tabular}{|c|c|c|c|c|c|c|}
\hline \multirow[b]{2}{*}{ Characteristic } & \multicolumn{3}{|c|}{ High-risk subjects } & \multicolumn{3}{|c|}{ Low-risk subjects } \\
\hline & CKD & Controls & P-value & CKD & Controls & P-value \\
\hline No. of subjects & 270 & 742 & & 164 & 1652 & \\
\hline Age (years) & $70.5 \pm 8.9$ & $66.3 \pm 9.5$ & $<0.0001$ & $71.8 \pm 8.8$ & $64.5 \pm 11.1$ & $<0.0001$ \\
\hline Gender (female/male, \%) & $36.3 / 63.7$ & $33.2 / 66.8$ & 0.3522 & $44.5 / 55.5$ & $53.0 / 47.0$ & 0.0374 \\
\hline Body mass index $\left(\mathrm{kg} / \mathrm{m}^{2}\right)$ & $23.5 \pm 3.7$ & $24.0 \pm 3.5$ & 0.0775 & $23.4 \pm 3.6$ & $22.9 \pm 3.1$ & 0.1426 \\
\hline Current or former smoker (\%) & 18.2 & 25.7 & 0.0104 & 28.1 & 24.9 & 0.3775 \\
\hline Systolic blood pressure $(\mathrm{mmHg})$ & $160 \pm 23$ & $153 \pm 22$ & 0.0001 & $132 \pm 11$ & $128 \pm 13$ & $<0.0001$ \\
\hline Diastolic blood pressure (mmHg) & $83 \pm 13$ & $83 \pm 14$ & 0.7738 & $74 \pm 7$ & $75 \pm 9$ & 0.0521 \\
\hline Fasting plasma glucose (mmol/l) & $9.40 \pm 3.28$ & $9.64 \pm 3.56$ & 0.3143 & $5.40 \pm 1.01$ & $5.94 \pm 1.23$ & $<0.0001$ \\
\hline Glycosylated hemoglobin (\%) & $7.20 \pm 1.14$ & $7.42 \pm 1.62$ & 0.0345 & $5.28 \pm 0.33$ & $5.20 \pm 0.34$ & 0.0083 \\
\hline Hypercholesterolemia (\%) & 53.0 & 52.7 & 0.9399 & 44.5 & 32.7 & 0.0027 \\
\hline Serum total cholesterol $(\mathrm{mmol} / \mathrm{l})$ & $5.35 \pm 0.94$ & $5.25 \pm 0.87$ & 0.1365 & $5.36 \pm 0.80$ & $5.20 \pm 0.74$ & 0.0127 \\
\hline Serum triglycerides $(\mathrm{mmol} / \mathrm{l})$ & $1.92 \pm 1.00$ & $1.78 \pm 1.04$ & 0.0561 & $1.76 \pm 0.74$ & $1.56 \pm 0.88$ & 0.0022 \\
\hline Serum HDL-cholesterol (mmol/l) & $1.27 \pm 0.38$ & $1.28 \pm 0.31$ & 0.5592 & $1.37 \pm 0.31$ & $1.47 \pm 0.33$ & 0.0001 \\
\hline Serum creatinine $(\mu \mathrm{mol} / \mathrm{l})$ & $154.7 \pm 159.9$ & $62.6 \pm 13.0$ & $<0.0001$ & $104.3 \pm 34.5$ & $60.8 \pm 12.1$ & $<0.0001$ \\
\hline eGFR (ml min $\left.{ }^{-1} 1.73 \mathrm{~m}^{-2}\right)$ & $38.8 \pm 11.9$ & $80.6 \pm 16.6$ & $<0.0001$ & $44.3 \pm 8.1$ & $78.9 \pm 17.6$ & $<0.0001$ \\
\hline End-stage renal disease $(\%)$ & 7.0 & 0 & $<0.0001$ & 0.6 & 0 & 0.0282 \\
\hline Myocardial infarction (\%) & 37.8 & 36.4 & 0.6855 & 15.2 & 9.1 & 0.0181 \\
\hline Ischemic stroke $(\%)$ & 27.4 & 24.3 & 0.3099 & 4.3 & 3.3 & 0.5413 \\
\hline
\end{tabular}

Quantitative data are means \pm SD. eGFR, estimated glomerular filtration rate; HDL, high-density lipoprotein.

and additive genetic models. Additive models included the additive 1 (heterozygotes versus wild-type homozygotes) and additive 2 (variant homozygotes versus wild-type homozygotes) models, which were analyzed simultaneously with a single statistical model. We also performed a stepwise forward selection procedure to examine the effects of genotypes as well as of other covariates on CKD; each genotype was examined according to a dominant or recessive model on the basis of statistical significance in the multivariable logistic regression analysis. The P-levels for inclusion in and exclusion from the model were 0.25 and 0.1 , respectively. A P-value $<0.05$ was considered statistically significant. Statistical significance was examined by two-sided tests performed with JMP version 6.0 software (SAS Institute, Cary, NC).

\section{Results}

Polymorphisms related to CKD in high-risk subjects. The characteristics of the 1012 high-risk subjects (668 men, 344 women) are shown in Table I. Age and systolic blood pressure were greater, whereas the percentage of smokers and blood glycosylated hemoglobin content were lower, in subjects with CKD than in controls.

Comparison of allele frequencies with the Chi-square test revealed that the $-519 \mathrm{~A} \rightarrow \mathrm{G}$ polymorphism of $M M P 1$, the $-3 \mathrm{~A} \rightarrow \mathrm{G}$ polymorphism of $A P O A 5$, the $\mathrm{A} \rightarrow \mathrm{G}($ Ile $1205 \mathrm{Val})$ polymorphism of $C O L 3 A 1$, the $-219 \mathrm{G} \rightarrow \mathrm{T}$ polymorphism of $A P O E$, the $\mathrm{A} \rightarrow \mathrm{G}$ (Lys45Glu) polymorphism of $M M P 3$, the $\mathrm{A} \rightarrow \mathrm{G}$ (Tyr243Cys) polymorphism of SERPINE1, the $1454 \mathrm{C} \rightarrow \mathrm{G}$ (Leu125Val) polymorphism of PECAM1, the
$1061 \mathrm{~A} \rightarrow \mathrm{G}$ (Ile $405 \mathrm{Val}$ ) polymorphism of $C E T P$, the $-863 \mathrm{C} \rightarrow \mathrm{A}$ polymorphism of $T N F$, and the $-1607 / 1 \mathrm{G} \rightarrow 2 \mathrm{G}$ polymorphism of $M M P 1$ were significantly $(\mathrm{P}<0.05)$ associated with the prevalence of CKD (Table II).

Multivariable logistic regression analysis with adjustment for age, gender, BMI, smoking status, and the prevalence of hypercholesterolemia revealed that the $-519 \mathrm{~A} \rightarrow \mathrm{G}$ polymorphism of MMP1 (dominant and additive 1 models), the $-3 \mathrm{~A} \rightarrow \mathrm{G}$ polymorphism of APOA5 (recessive and additive 2 models), the $\mathrm{A} \rightarrow \mathrm{G}$ (Ile1205Val) polymorphism of COL $3 \mathrm{Al}$ (dominant and additive 1 models), the $-219 \mathrm{G} \rightarrow \mathrm{T}$ polymorphism of $A P O E$ (dominant, recessive, and additive 1 and 2 models), the $\mathrm{A} \rightarrow \mathrm{G}$ (Lys45Glu) polymorphism of MMP3 (dominant and additive 1 and 2 models), the $1454 \mathrm{C} \rightarrow \mathrm{G}$ (Leu125Val) polymorphism of PECAMI (dominant and additive 2 models), the $1061 \mathrm{~A} \rightarrow \mathrm{G}(\mathrm{Ile} 405 \mathrm{Val})$ polymorphism of CETP (dominant and additive 1 and 2 models), the $-863 \mathrm{C} \rightarrow \mathrm{A}$ polymorphism of TNF (dominant and additive 1 models), and the $-1607 / 1 \mathrm{G} \rightarrow 2 \mathrm{G}$ polymorphism of $M M P 1$ (dominant and additive 1 and 2 models) were significantly $(\mathrm{P}<0.05)$ associated with the prevalence of CKD (Table III). The variant $G$ allele of the $-519 \mathrm{~A} \rightarrow \mathrm{G}$ polymorphism of $M M P 1, T$ allele of $A P O E$, and $G$ allele of $P E C A M 1$ were risk factors for CKD, whereas the $G$ allele of $A P O A 5, G$ allele of $C O L 3 A 1, G$ allele of $M M P 3$, $G$ allele of CETP, $A$ allele of TNF, and $2 G$ allele of the $-1607 / 1 \mathrm{G} \rightarrow 2 \mathrm{G}$ polymorphism of $M M P 1$ were protective against this condition.

A stepwise forward selection procedure was performed to examine the effects of genotypes for the nine polymorphisms associated with CKD by multivariable logistic regression 
Table II. Genotype distributions of polymorphisms related (allele frequency, $\mathrm{P}<0.05$ ) to chronic kidney disease $(\mathrm{CKD})$ in high-risk subjects as determined by the Chi-square test.

\begin{tabular}{|c|c|c|c|c|c|c|}
\hline $\begin{array}{l}\text { Gene } \\
\text { symbol }\end{array}$ & Polymorphism & dbSNP & CKD & Controls & $\begin{array}{c}\text { P-value } \\
\text { (genotype) }\end{array}$ & $\begin{array}{c}\text { P-value } \\
\text { (allele frequency) }\end{array}$ \\
\hline$M M P 1$ & $\begin{array}{c}-519 \mathrm{~A} \rightarrow \mathrm{G} \\
A A \\
A G \\
G G\end{array}$ & rs1144393 & $\begin{array}{r}206(76.3) \\
59(21.8) \\
5 \quad(1.9)\end{array}$ & $\begin{array}{r}631(85.0) \\
106(14.3) \\
5 \quad(0.7)\end{array}$ & 0.0044 & 0.0009 \\
\hline APOA5 & $\begin{array}{c}-3 \mathrm{~A} \rightarrow \mathrm{G} \\
A A \\
A G \\
G G\end{array}$ & rs651821 & $\begin{array}{r}94(12.1) \\
368(47.3) \\
316(40.6)\end{array}$ & $\begin{array}{r}482(10.9) \\
1901(42.8) \\
2055(46.3)\end{array}$ & 0.0142 & 0.0078 \\
\hline COL3AI & $\begin{array}{c}\mathrm{A} \rightarrow \mathrm{G}(\mathrm{Ile} 1205 \mathrm{Val}) \\
A A \\
A G \\
G G\end{array}$ & rs2271683 & $\begin{array}{r}232(85.9) \\
37(13.7) \\
1 \quad(0.4)\end{array}$ & $\begin{array}{r}584(78.7) \\
151(20.4) \\
7 \quad(0.9)\end{array}$ & 0.0268 & 0.0079 \\
\hline$A P O E$ & $\begin{array}{c}-219 \mathrm{G} \rightarrow \mathrm{T} \\
G G \\
G T \\
T T\end{array}$ & rs405509 & $\begin{array}{r}14(5.2) \\
105(38.9) \\
151(55.9)\end{array}$ & $\begin{array}{r}73(9.9) \\
306(41.2) \\
363(48.9)\end{array}$ & 0.0215 & 0.0097 \\
\hline MMP3 & $\begin{array}{c}\mathrm{A} \rightarrow \mathrm{G}(\mathrm{Lys} 45 \mathrm{Glu}) \\
A A \\
A G \\
G G\end{array}$ & rs679620 & $\begin{array}{r}39(14.5) \\
114(42.2) \\
117(43.3)\end{array}$ & $\begin{array}{r}58(7.8) \\
331(44.6) \\
353(47.6)\end{array}$ & 0.0092 & 0.0208 \\
\hline SERPINE1 & $\begin{array}{c}\mathrm{A} \rightarrow \mathrm{G}(\text { Tyr243Cys }) \\
A A \\
A G \\
G G\end{array}$ & rs13306846 & $\begin{array}{rr}268 & (99.3) \\
2 & (0.7) \\
0 & (0.0)\end{array}$ & $\begin{array}{rr}742 & (100) \\
0 & (0) \\
0 & (0)\end{array}$ & 0.0214 & 0.0214 \\
\hline PECAMI & $\begin{array}{c}1454 \mathrm{C} \rightarrow \mathrm{G}(\text { Leu125Val }) \\
C C \\
C G \\
G G\end{array}$ & rs668 & $\begin{array}{r}50(18.5) \\
145(53.7) \\
75(27.8)\end{array}$ & $\begin{array}{l}190(25.6) \\
379(51.1) \\
173(23.3)\end{array}$ & 0.0440 & 0.0215 \\
\hline CETP & $\begin{array}{c}1061 \mathrm{~A} \rightarrow \mathrm{G}(\mathrm{Ile} 405 \mathrm{Val}) \\
A A \\
A G \\
G G\end{array}$ & rs5882 & $\begin{array}{r}79(29.3) \\
124(45.9) \\
67(24.8)\end{array}$ & $\begin{array}{l}149(20.1) \\
395(53.2) \\
198(26.7)\end{array}$ & 0.0092 & 0.0279 \\
\hline$T N F$ & $\begin{array}{c}-863 \mathrm{C} \rightarrow \mathrm{A} \\
C C \\
C A \\
A A\end{array}$ & rs1800630 & $\begin{array}{r}209(77.4) \\
55(20.4) \\
6 \quad(2.2)\end{array}$ & $\begin{array}{r}516(69.5) \\
210(28.3) \\
16 \quad(2.2)\end{array}$ & 0.0351 & 0.0280 \\
\hline$M M P 1$ & $\begin{array}{c}-1607 / 1 \mathrm{G} \rightarrow 2 \mathrm{G} \\
1 G 1 G \\
1 G 2 G \\
2 G 2 G\end{array}$ & rs 1799750 & $\begin{array}{r}40(14.8) \\
113(41.9) \\
117(43.3)\end{array}$ & $\begin{array}{r}68(9.1) \\
324(43.7) \\
350(47.2)\end{array}$ & 0.0424 & 0.0446 \\
\hline
\end{tabular}

analysis as well as of age, gender, BMI, smoking status, and the prevalence of hypercholesterolemia on CKD (Table IV). Age, $M M P 3$ genotype (dominant model), CETP genotype (dominant model), APOE genotype (dominant model), MMP1 genotype (the $-519 \mathrm{~A} \rightarrow \mathrm{G}$ polymorphism, dominant model), COL3A1 genotype (dominant model), TNF genotype (dominant model), and PECAMI genotype (dominant model) in descending order of statistical significance, were significant $(\mathrm{P}<0.05)$ and independent determinants of CKD.

Polymorphisms related to CKD in low-risk subjects. The characteristics of the 1816 low-risk subjects (867 men, 949 


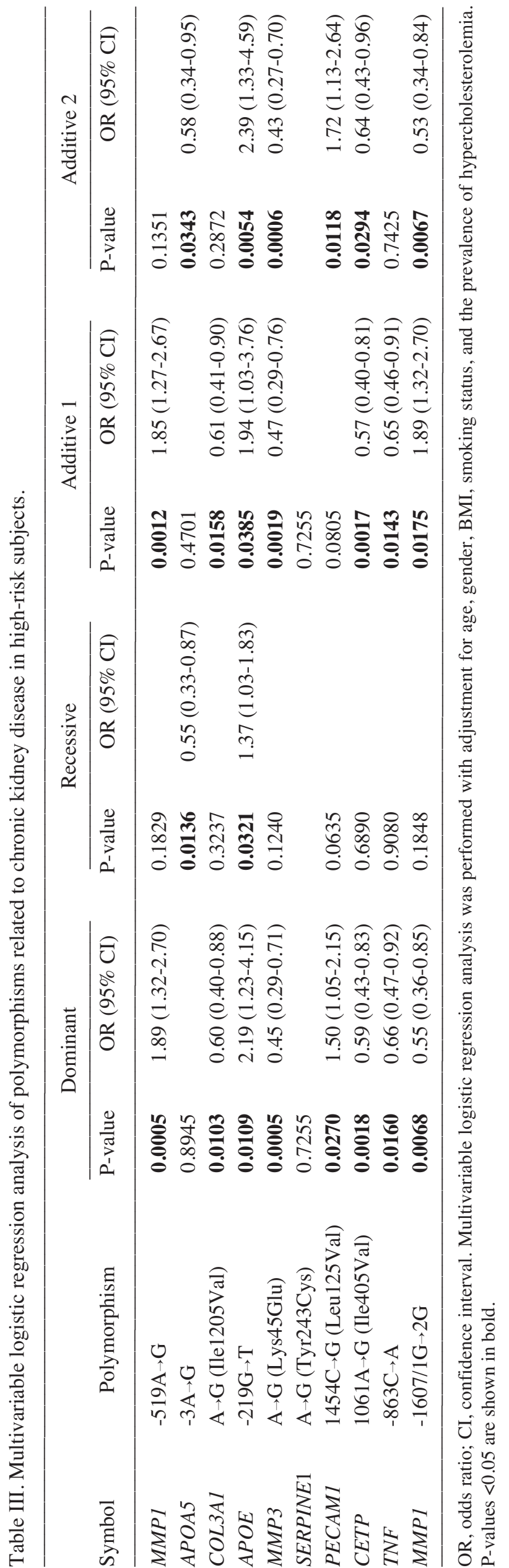

Table IV. Effects of genotypes and other characteristics on the prevalence of chronic kidney disease in high-risk subjects as determined by a stepwise forward selection procedure.

\begin{tabular}{lrc}
\hline Variable & P-value & $\mathrm{R}^{2}$ \\
\hline Age & $<0.0001$ & 0.0365 \\
$M M P 3(G G+A G$ versus $A A)$ & 0.0007 & 0.0098 \\
CETP $(G G+A G$ versus $A A)$ & 0.0020 & 0.0082 \\
APOE $(T T+G T$ versus $G G)$ & 0.0046 & 0.0069 \\
$M M P 1(G G+A G$ versus $A A)$ & 0.0066 & 0.0063 \\
$C O L 3 A 1(G G+A G$ versus $A A)$ & 0.0131 & 0.0053 \\
TNF $(A A+C A$ versus $C C)$ & 0.0166 & 0.0049 \\
PECAMI $(G G+C G$ versus $C C)$ & 0.0430 & 0.0035 \\
\hline
\end{tabular}

$\mathrm{R}^{2}$, contribution rate.

women) are shown in Table I. Age, the frequency of male subjects, systolic blood pressure, blood glycosylated hemoglobin content, the prevalence of hypercholesterolemia and myocardial infarction, as well as the serum concentrations of total cholesterol and triglycerides were greater, whereas fasting plasma glucose level and the serum concentration of highdensity lipoprotein cholesterol were lower in subjects with CKD than in controls.

Comparison of allele frequencies with the Chi-square test revealed that the $1167 \mathrm{C} \rightarrow \mathrm{T}$ (Asn389Asn) polymorphism of $T G F B R 2$, the $2386 \mathrm{~A} \rightarrow \mathrm{G}$ (Ile796Val) polymorphism of $S C A P$, and the TAAA $\rightarrow$ del polymorphism of $P D E 4 D$ were significantly $(\mathrm{P}<0.05)$ associated with the prevalence of $\mathrm{CKD}$ (Table V).

Multivariable logistic regression analysis with adjustment for age, gender, BMI, smoking status, and the prevalence of hypercholesterolemia revealed that the $1167 \mathrm{C} \rightarrow \mathrm{T}$ (Asn389Asn) polymorphism of TGFBR2 (dominant and additive 1 and 2 models), the $2386 \mathrm{~A} \rightarrow \mathrm{G}$ (Ile796Val) polymorphism of $S C A P$ (recessive and additive 2 models), and the TAAA $\rightarrow$ del polymorphism of $P D E 4 D$ (recessive and additive 2 models) were significantly $(\mathrm{P}<0.05)$ associated with the prevalence of $C K D$ (Table VI). The variant $G$ allele of SCAP and deletion allele of $P D E 4 D$ were risk factors for CKD, whereas the variant $T$ allele of $T G F B R 2$ was protective against this condition.

A stepwise forward selection procedure was performed to examine the effects of genotypes for the three polymorphisms associated with CKD by multivariable logistic regression analysis as well as of age, gender, BMI, smoking status, and the prevalence of hypercholesterolemia on CKD (Table VII). Age, hypercholesterolemia, BMI, PDE4D genotype (recessive model), TGFBR2 genotype (dominant model), and SCAP genotype (recessive model) in descending order of statistical significance, were significant $(\mathrm{P}<0.05)$ and independent determinants of CKD.

\section{Discussion}

We examined the possible relations of 296 polymorphisms of 202 candidate genes to the prevalence of CKD in high- or 
Table V. Genotype distributions of polymorphisms related (allele frequency, $\mathrm{P}<0.05$ ) to chronic kidney disease $(\mathrm{CKD})$ in lowrisk subjects as determined by the Chi-square test.

\begin{tabular}{|c|c|c|c|c|c|c|}
\hline $\begin{array}{l}\text { Gene } \\
\text { symbol }\end{array}$ & Polymorphism & dbSNP & CKD & Controls & $\begin{array}{c}\text { P-value } \\
\text { (genotype) }\end{array}$ & $\begin{array}{c}\mathrm{P} \text {-value } \\
\text { (allele frequency) }\end{array}$ \\
\hline$T G F B R 2$ & $\begin{array}{r}1167 \mathrm{C} \rightarrow \mathrm{T}(\text { Asn389Asn }) \\
C C \\
C T \\
T T\end{array}$ & rs2228048 & $\begin{array}{r}105(64.0) \\
53(32.3) \\
6 \quad(3.7)\end{array}$ & $\begin{array}{l}848(51.4) \\
677(41.0) \\
126 \quad(7.6)\end{array}$ & 0.0038 & 0.0009 \\
\hline$S C A P$ & $\begin{array}{c}2386 \mathrm{~A} \rightarrow \mathrm{G}(\text { Ile } 796 \mathrm{Val}) \\
A A \\
A G \\
G G\end{array}$ & rs12487736 & $\begin{array}{l}38(23.3) \\
75(45.7) \\
51(31.1)\end{array}$ & $\begin{array}{l}472(28.7) \\
819(49.7) \\
355(21.6)\end{array}$ & 0.0218 & 0.0094 \\
\hline$P D E 4 D$ & $\begin{array}{c}\text { TAAA } \rightarrow \text { del } \\
T A A A / T A A A \\
T A A A / \text { del } \\
\text { del } / \text { del }\end{array}$ & rs3839219 & $\begin{array}{l}96(58.5) \\
54(32.9) \\
14 \quad(8.6)\end{array}$ & $\begin{array}{r}1048(63.5) \\
536(32.5) \\
67 \quad(4.0)\end{array}$ & 0.0492 & 0.0494 \\
\hline
\end{tabular}

low-risk subjects separately. Our association study with three steps of analysis (Chi-square test, multivariable logistic regression analysis, and stepwise forward selection procedure) revealed that ten different polymorphisms were associated with the prevalence of CKD in high- or low-risk subjects. Among these polymorphisms, the $-519 \mathrm{~A} \rightarrow \mathrm{G}$ polymorphism of $M M P 1$ and the $1167 \mathrm{C} \rightarrow \mathrm{T}$ (Asn389Asn) polymorphism of TGFBR2 were most significantly associated with CKD in high- and low-risk individuals, respectively.

Matrix metallopeptidase 1 (MMP1) degrades fibrillar collagens, especially types I and III, which are resistant to most other proteinases (18). The $-519 \mathrm{~A} \rightarrow \mathrm{G}$ polymorphism of $M M P 1$, which is located in the promoter region of the gene, has been associated with the risk of myocardial infarction as part of a haplotype including other polymorphisms of $M M P 1$ (19). In addition, the $G$ allele of this polymorphism was associated with an increased intima-media thickness of the carotid artery in a German population with hypertension (20). We now showed that the $-519 \mathrm{~A} \rightarrow \mathrm{G}$ polymorphism of $M M P 1$ was significantly associated with the prevalence of CKD in high-risk subjects, with the $G$ allele representing a risk factor for this condition. Effects of this polymorphism on the development of atherosclerosis may account for its association with CKD.

Transforming growth factor, $\beta$ receptor II (TGFBR2) forms a heterodimeric complex with TGFBR1 and binds to transforming growth factor, $B 1$ which is a multifunctional cytokine implicated in the pathogenesis of many forms of progressive renal disease (21). It has been proposed that upregulation of TGFBR2 induced by high extracellular glucose may contribute to distal tubular hypertrophy in diabetic nephropathy (22). TGFBR2 is composed of seven exons and maps to 3p22 (23). Although the $869 \mathrm{~T} \rightarrow \mathrm{C}$ (Leu10Pro) polymorphism of TGFBR2 was shown to be associated with diabetic nephropathy (24), the $1167 \mathrm{C} \rightarrow \mathrm{T}$ (Asn389Asn) polymorphism has not previously been associated with this condition. We now showed that the $1167 \mathrm{C} \rightarrow \mathrm{T}$ (Asn389Asn) polymorphism of TGFBR2 was significantly associated with the prevalence of CKD in lowrisk subjects, with the $T$ allele being protective against this condition, although the molecular mechanism underlying this association remains to be elucidated.

We found that six and two polymorphisms were also related to the prevalence of CKD in high- or low-risk subjects, respectively, with none of these polymorphisms having previously been shown to be associated with CKD. The $-219 \mathrm{G} \rightarrow \mathrm{T}$ polymorphism of $A P O E$ was previously associated with myocardial infarction in men in France and Northern Ireland, with the $T$ allele representing a risk factor for this condition (25). The $T$ allele of this polymorphism was also shown to be a risk factor for coronary heart disease in lowrisk Japanese men (26). Although the $-308 \mathrm{G} \rightarrow \mathrm{A}$ polymorphism of TNF $(27,28)$ was shown to be associated with CKD, the $-863 \mathrm{C} \rightarrow \mathrm{A}$ polymorphism of $T N F$ has not previously been associated with this condition. The $A$ allele of the $-863 \mathrm{C} \rightarrow \mathrm{A}$ polymorphism of $T N F$ was shown to be protective against the development of coronary heart disease in Japanese men without type 2 diabetes (29). We previously showed that the $-1171 / 5 \mathrm{~A} \rightarrow 6 \mathrm{~A}$ polymorphism of $M M P 3$ was associated with the prevalence of myocardial infarction in Japanese women (30). The $6 \mathrm{~A}$ allele of this polymorphism was also associated with increased intima-media thickness of the carotid artery (31). These various observations implicate $M M P 3$ as a candidate gene for atherosclerosis. The $\mathrm{G} \rightarrow \mathrm{A}$ (Gly670Arg) polymorphism of PECAMI was associated with an increased risk of myocardial infarction in Japanese (32), with the $A$ allele representing a risk factor for this condition. The $G$ allele of the $1061 \mathrm{~A} \rightarrow \mathrm{G}$ (Ile405Val) polymorphism in CETP has been associated with an independent risk factor for coronary heart disease in white women, despite being related to the increased levels of high-density lipoprotein cholesterol (33). EhlersDanlos syndrome type IV, the vascular type, results from mutations in COL3A1 (34). The 2386A $\rightarrow \mathrm{G}$ (Ile796Val) polymorphism of SCAP was associated with the serum concentrations of total cholesterol and triglycerides in response to 
Table VII. Effects of genotypes and other characteristics on the prevalence of chronic kidney disease in low-risk subjects as determined by a stepwise forward selection procedure.

\begin{tabular}{lrc}
\hline Variable & P-value & $\mathrm{R}^{2}$ \\
\hline Age & $<0.0001$ & 0.0702 \\
Hypercholesterolemia & 0.0006 & 0.0108 \\
Body mass index & 0.0031 & 0.0080 \\
$P D E 4 D$ & 0.0067 & 0.0067 \\
(del/del versus $T A A A / T A A A+T A A A / \mathrm{del})$ & & \\
$T G F B R 2(T T+C T$ versus $C C)$ & 0.0071 & 0.0066 \\
$S C A P(G G$ versus $A A+G A)$ & 0.0077 & 0.0064 \\
\hline
\end{tabular}

$\mathrm{R}^{2}$, contribution rate.

simvastatin treatment (35). Single nucleotide polymorphisms of PDE4D were associated with increased risk of ischemic stroke in nonhypertensive subjects in a prospective study of American women over age 65 years (36).

Our study has several limitations: i) We used an estimated glomerular filtration rate (eGFR) instead of a directly measured rate to define CKD. ii) We were not able to obtain information on the underlying renal disease or the primary cause of CKD in each subject with CKD. iii) It is possible that one or more of the polymorphisms associated with CKD in the present study are in linkage disequilibrium with other polymorphisms in the same gene or in other nearby genes that are actually responsible for the development of this condition. iv) The functional relevance of the identified polymorphisms to gene transcription or to protein structure or function was not determined in the present study. v) Given the multiple comparisons of genotypes with CKD, it is not possible to exclude completely potential statistical errors such as false positives. Our present study can thus be considered as hypothesis generating.

In conclusion, our present results suggest that polymorphisms associated with CKD may differ among high- or low-risk subjects. Stratification of subjects according to conventional risk factors may thus be important for personalized prevention of CKD based on genetic information. Validation of our findings will require their replication with independent subject panels.

\section{Acknowledgements}

In addition to the authors, the following investigators participated in the study: H. Matsuo and T. Segawa (Gifu Prefectural General Medical Center); T. Hibino, K. Yajima, T. Fujimaki, and T. Kawamiya (Gifu Prefectural Tajimi Hospital); A. Yasunaga, H. Park, N. Fuku, M. Tanaka, T. Suzuki, and H. Yoshida (Tokyo Metropolitan Institute of Gerontology). We also thank nursing and laboratory staff of the participating hospitals. This work was supported in part by Grants-in-Aid for Scientific Research from the Ministry of Education, Culture, Sports, Science, and Technology of Japan (nos. 18209023, 18018021 and 19659149 to Y.Y.). 


\section{References}

1. Weiner DE, Tighiouart H, Amin MG, et al: Chronic kidney disease as a risk factor for cardiovascular disease and all-cause mortality: a pooled analysis of community-based studies. J Am Soc Nephrol 15: 1307-1315, 2004

2. Jafar TH, Stark PC, Schmid CH, et al: Progression of chronic kidney disease: the role of blood pressure control, proteinuria, and angiotensin-converting enzyme inhibition: a patient-level meta-analysis. Ann Intern Med 139: 244-252, 2003.

3. Haroun MK, Jaar BG, Hoffman SC, Comstock GW, Klag MJ and Coresh J: Risk factors for chronic kidney disease: a prospective study of 23,534 men and women in Washington County, Maryland. J Am Soc Nephrol 14: 2934-2941, 2003.

4. Ravera M, Re M, Deferrari L, Vettoretti S and Deferrari G: Importance of blood pressure control in chronic kidney disease. J Am Soc Nephrol 17 (4 Suppl 2): 98-103, 2006.

5. Yamagata K, Ishida K, Sairenchi T, et al: Risk factors for chronic kidney disease in a community-based population: a 10year follow-up study. Kidney Int 71: 159-166, 2007.

6. Iseki K: Chronic kidney disease in Japan from early predictions to current facts. Nephron Clin Pract 110: c268-c272, 2008

7. Jee SH, Boulware LE, Guallar E, Suh I, Appel LJ and Miller ER III: Direct, progressive association of cardiovascular risk factors with incident proteinuria: results from the Korea Medical Insurance Corporation (KMIC) study. Arch Intern Med 165: 2299-2304, 2005

8. Korstanje R and DiPetrillo K: Unraveling the genetics of chronic kidney disease using animal models. Am J Physiol Renal Physiol 287: F347-F352, 2004.

9. Perneger TV, Whelton PK and Klag MJ: Race and end-stage renal disease. Socioeconomic status and access to health care as mediating factors. Arch Intern Med 155: 1201-1208, 1995.

10. National Kidney Foundation: K/DOQI clinical practice guidelines for chronic kidney disease: evaluation, classification, and stratification. Am J Kidney Dis 39 (2 Suppl 1): 1-266, 2002.

11. Gharavi AG, Yan Y, Scolari F, et al: IgA nephropathy, the most common cause of glomerulonephritis, is linked to 6q22-23. Nat Genet 26: 354-357, 2000

12. Hanson RL, Craig DW and Millis MP: Identification of PVT1 as a candidate gene for end-stage renal disease in type 2 diabetes using a pooling-based genome-wide single nucleotide polymorphism association study. Diabetes 56: 975-983, 2007.

13. Doi K, Noiri E, Nakao A, Fujita T, Kobayashi S and Tokunaga K: Functional polymorphisms in the vascular endothelial growth factor gene are associated with development of end-stage renal disease in males. J Am Soc Nephrol 17: 823-830, 2006

14. Wetmore JB, Hung AM, Lovett DH, Sen S, Quershy O and Johansen KL: Interleukin-1 gene cluster polymorphisms predict risk of ESRD. Kidney Int 68: 278-284, 2005.

15. Imai E, Matsuo S, Makino H, et al: Chronic Kidney Disease Japan Cohort (CKD-JAC) study: design and methods. Hypertens Res 31: 1101-1107, 2008

16. Go AS, Chertow GM, Fan D, McCulloch CE and Hsu CY: Chronic kidney disease and the risks of death, cardiovascular events, and hospitalization. N Engl J Med 351: 1296-1305, 2004.

17. Itoh Y, Mizuki N, Shimada T, et al: High-throughput DNA typing of HLA-A, -B, -C, and -DRB1 loci by a PCR-SSOPLuminex method in the Japanese population. Immunogenetics 57: 717-729, 2005.

18. Visse R and Nagase H: Matrix metalloproteinases and tissue inhibitors of metalloproteinases: structure, function, and biochemistry. Circ Res 92: 827-839, 2003.

19. Pearce E, Tregouet DA, Samnegård A, et al: Haplotype effect of the matrix metalloproteinase-1 gene on risk of myocardial infarction. Circ Res 97: 1070-1076, 2005.
20. Armstrong C, Abilleira S, Sitzer M, Markus HS and Bevan S: Polymorphisms in MMP family and TIMP genes and carotid artery intima-media thickness. Stroke 38: 2895-2899, 2007.

21. Reeves WB and Andreoli TE: Transforming growth factor beta contributes to progressive diabetic nephropathy. Proc Natl Acad Sci USA 97: 7667-7669, 2000.

22. Yang YL, Guh JY, Yang ML, et al: Interaction between high glucose and TGF-beta in cell cycle protein regulations in MDCK cells. J Am Soc Nephrol 9: 182-193, 1998.

23. Mathew S, Murty VV, Cheifetz S, George D, Massagué J and Chaganti RS: Transforming growth factor receptor gene TGFBR2 maps to human chromosome band 3p22. Genomics 20: 114-115, 1994

24. Wong TY, Poon P, Chow KM, Szeto CC, Cheung MK and Li PK: Association of transforming growth factor-beta (TGF-beta) T869C (Leu10Pro) gene polymorphisms with type 2 diabetic nephropathy in Chinese. Kidney Int 63: 1831-1835, 2003

25. Lambert JC, Brousseau T, Defosse V, et al: Independent association of an APOE gene promoter polymorphism with increased risk of myocardial infarction and decreased APOE plasma concentrations - the ECTIM study. Hum Mol Genet 9: 57-61, 2000.

26. Hirashiki A, Yamada Y, Murase Y, et al: Association of gene polymorphisms with coronary artery disease in low- or high-risk subjects defined by conventional risk factors. J Am Coll Cardiol 42: 1429-1437, 2003

27. Thibaudin D, Thibaudin L, Berthoux P, et al: TNFA2 and $\mathrm{d} 2$ alleles of the tumor necrosis factor alpha gene polymorphism are associated with onset/occurrence of idiopathic membranous nephropathy. Kidney Int 71: 431-437, 2007.

28. Buraczynska M, Mierzicki P, Buraczynska K, Dragan M and Ksiazek A: Tumor necrosis factor-alpha gene polymorphism correlates with cardiovascular disease in patients with end-stage renal disease. Mol Diagn Ther 11: 257-263, 2007.

29. Yamada Y, Ichihara S, Izawa H, Tanaka M, et al: Genetic risk for coronary artery disease in individuals with or without type 2 diabetes. Mol Genet Metab 81: 282-290, 2004.

30. Yamada Y, Izawa H, Ichihara S, et al: Prediction of the risk of myocardial infarction from polymorphisms in candidate genes. N Engl J Med 347: 1916-1923, 2002.

31. Rundek T, Elkind MS, Pittman J, et al: Carotid intima-media thickness is associated with allelic variants of stromelysin-1, interleukin-6, and hepatic lipase genes: the Northern Manhattan Prospective Cohort Study. Stroke 33: 1420-1423, 2002.

32. Sasaoka T, Kimura A, Hohta SA, Fukuda N, Kurosawa T and Izumi T: Polymorphisms in the platelet-endothelial cell adhesion molecule-1 (PECAM-1) gene, Asn563Ser and Gly670Arg, associated with myocardial infarction in the Japanese. Ann NY Acad Sci 947: 259-269, 2001.

33. Agerholm-Larsen B, Nordestgaard BG, Steffensen R, Jensen G and Tybjaerg-Hansen A: Elevated HDL cholesterol is a risk factor for ischemic heart disease in white women when caused by a common mutation in the cholesteryl ester transfer protein gene. Circulation 101: 1907-1912, 2000.

34. Pepin M, Schwarze U, Superti-Furga A and Byers PH: Clinical and genetic features of Ehlers-Danlos syndrome type IV, the vascular type. N Engl J Med 342: 673-680, 2000.

35. Fiegenbaum M, Silveira FR, Van der Sand CR, et al: Determinants of variable response to simvastatin treatment: the role of common variants of SCAP, SREBF-1a and SREBF-2 genes. Pharmacogenomics J 5: 359-364, 2005.

36. Brophy VH, Ro SK, Rhees BK, et al: Association of phosphodiesterase 4D polymorphisms with ischemic stroke in a US population stratified by hypertension status. Stroke 37: 1385-1390, 2006. 